\title{
A RACIONALIZAÇÃO DO SISTEMA JUDICIAL NO BRASIL: DESAFIOS E PERSPECTIVAS
}

RESUMO: À medida que a necessidade de implementação de diretrizes nacionais exigiu a racionalização do sistema judicial para nortear a atuação institucional, fez também com que o Judiciário brasileiro incorporasse à sua agenda categorias até então desconhecidas. Em contrapartida, houve um incremento notável de suas funções "secundárias" de normatização e administração na tentativa de aperfeiçoar a prestação dos serviços judiciários. Essa nova realidade insere a racionalização do sistema judicial brasileiro em um contexto complexo, dinâmico e de intensas transformações, onde os atores não só disputam espaços como ganham diferentes papéis, impondo não somente novas demandas, mas, também, novas relações.

Palavras-chave: Reforma do Estado. Reforma Judiciária. Racionalização judicial.
ABSTRACT: As the need to implement national guidelines required the rationalization of the judicial system to guide institutional action, it also made the brazilian judiciary incorporate previously unknown categories into its agenda. On the other hand, there was a notable increase in its "secondary" functions of standardization and administration in an attempt to improve the provision of judicial services. This new reality introduces the rationalization of the brazilian judicial system in a complex, dynamic and intensely transformative context where actors not only compete for spaces but gain different roles, imposing not only new demands, but also new relationships.

Keywords: Reform of the State. Judicial reform. Judicial racionalization.

1 Doutor em Sociologia Jurídica, CIES-IUL-Lisboa. Pesquisador do Centro de Investigação e Estudos em Sociologia do Instituto Universitário de Lisboa (CIES-IUL). Professor universitário, com estudos e pesquisas em Administração da Justiça e Política Judiciária. 


\section{INTRODUÇÃO}

Em 18 de março de 2009, foi publicada, pelo Conselho Nacional de Justiça (CNJ), a Resolução $n^{\circ}$ 70, que dispõe sobre o "Planejamento e Gestão Estratégica no âmbito do Poder Judiciário"², atendendo à exigência de implementação de diretrizes nacionais para nortear a atuação institucional, conforme deliberado pelos presidentes dos tribunais brasileiros, no I Encontro Nacional do Judiciário, realizado em Brasília, em 2008.

A pauta do Encontro está inserida no contexto de reforma do Estado e articulado aos processos de reordenação institucional e de reestruturação da relação Estado, Direito e Sociedade, que impõem um rearranjo dos papéis e das relações institucionais assim como mudanças estruturais e procedimentais das instituições democráticas.

Sob esse novo modelo institucional o "Planejamento e Gestão Estratégica no âmbito do Poder Judiciário" (Res. $\mathrm{n}^{\circ}$ 70, de 18 de março de 2009, do CNJ) ganha um sentido mais amplo - não só de reforma do Judiciário, mas do próprio Estado - apresentando como consequência imediata a implementação de diretrizes nacionais para nortear a atuação institucional a fim de aperfeiçoar e modernizar os serviços judiciais e conferir maior continuidade administrativa aos tribunais.

No entanto, à medida que a necessidade de implementação de diretrizes nacionais exigiu a racionalização judicial para nortear a atuação institucional, fez também com que o Judiciário incorporasse à sua agenda categorias até então desconhecidas de suas práticas cotidianas. Em contrapartida, houve um incremento notável de suas funções "secundárias" de normatização e administração na tentativa de aperfeiçoar a prestação dos serviços judiciários.

No entanto, o incremento das funções de normatização e administração constitui apenas uma parte da racionalização do sistema judicial, que será veementemente contestada quando, sob os fundamentos de modernização e eficiência, permite, por exemplo, a coexistência de situações que ameaçam direitos de cidadania - exatamente os

\footnotetext{
${ }^{2}$ Considerando a necessidade de revisar a Res. n 70, de 2009, do CNJ (que "Dispõe sobre o Planejamento e a Gestão Estratégica no âmbito do Poder Judiciário"), em 2014 foi publicada pelo CNJ, a Res. n 198, com o mesmo título.
} 
quais propõe promover -, colocando em questão tal racionalidade e seus objetivos especialmente, o acesso à justiça -, que justificam o planejamento estratégico do Poder Judiciário em sua atuação institucional.

É a partir desta realidade concreta que este artigo faz uma análise inicial da racionalização do sistema judicial brasileiro sob a reordenação institucional e a reestruturação da relação Estado, Direito e Sociedade, e inserida em um contexto complexo, dinâmico e de intensas transformações, onde os atores não só disputam espaços como ganham diferentes papéis, impondo não somente novas demandas, mas, também, novas relações.

A análise se divide em três partes. A primeira parte destaca o modelo institucional a partir da Constituição de 1988, que inaugura um novo parâmetro para o "Planejamento e Gestão Estratégica no âmbito do Poder Judiciário" (Res. n 70, de 18 de março de 2009, do CNJ), que determinará a implementação de diretrizes nacionais para nortear a atuação institucional a fim de aperfeiçoar e modernizar os serviços judiciais.

A segunda parte contextualiza a reforma do Estado na América Latina e no Brasil, descrevendo como as novas democracias latino-americanas - e, consequentemente, as suas reformas - se inserem neste contexto, destacando, no caso do Brasil, como o objetivo fiscal de redução dos gastos do governo associa-se às promessas de mais eficiência no uso dos recursos públicos e de mais qualidade dos serviços prestados à população com novas práticas de transparência e maior responsabilização dos governos.

A terceira e última parte analisa a racionalização do sistema judicial brasileiro, apontado a coexistência de fatores e de interesses diversos - e às vezes opostos - a partir da qual o Judiciário buscará nortear a sua atuação institucional pautada em um planejamento estratégico nacional, que consiste no desenvolvimento de políticas judiciárias, cujos desafios e perspectivas impõem uma redefinição do seu papel.

\section{O MODELO INSTITUCIONAL}

O desenvolvimento institucional no Brasil se deu de forma bastante atribulada, de modo que a experiência democrática brasileira sofreu sucessivas interrupções desde a Primeira República até a Constituição de 1988, que trouxe um novo modelo institucional 
pautado em princípios de reordenação institucional e de reestruturação da relação EstadoDireito-Sociedade.

É preciso destacar, no entanto, que neste novo modelo as mudanças institucionais decorrentes da luta pela redemocratização ocorrida no país não se limitam apenas a aspectos formais de reordenação institucional e de reestruturação das relações. A ideia de democracia sempre esteve indissociavelmente relacionada - inclusive nos vários movimentos de luta pela redemocratização - à reivindicação de justiça social (ALMEIDA, 2003).

Diversamente dos modelos institucionais precedentes, que se limitavam apenas a rearranjos formais, a República Federativa do Brasil, então constituída em Estado Democrático de Direito, com a Constituição de 1988, tem um sentido de conteúdo transformador da realidade que, dada a sua substancialidade - e para além de seu formalismo -, incorpora a natureza inacabada da democracia, apresentando-se como uma contínua (re)criação e assumindo um caráter dinâmico diverso da sua porção estática formal.

É com base nesse novo modelo institucional, e em vista das demandas do contexto social, político e econômico - bem como das exigências de organismos internacionais, como o Banco Mundial (1996) -, que o “Planejamento e Gestão Estratégica no âmbito do

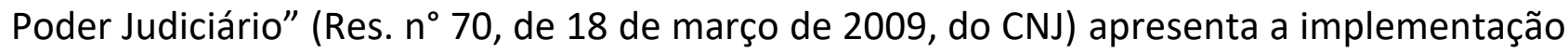
de diretrizes nacionais para nortear a atuação institucional a fim de aperfeiçoar e modernizar os serviços judiciais e conferir maior continuidade administrativa aos tribunais, incorporando, inclusive, categorias até então desconhecidas do Judiciário, como planejamento estratégico e gestão institucional.

\subsection{Planejamento estratégico e gestão institucional}

Em dezembro de 2015 foi aprovado na Sessão Plenária do CNJ o "Plano Estratégico do CNJ para o período 2015-2020". Instituído por meio da Portaria n 167, de 15 dezembro de 2015, o Plano Estratégico apresenta como componentes da estratégia do CNJ, dentre outros: o desenvolvimento de políticas judiciárias que promovam a efetividade e a unidade do Poder Judiciário, orientadas para valores de justiça e paz social, de modo a ser 
reconhecido como órgão de excelência em planejamento estratégico, governança e gestão judiciária ${ }^{3}$, visando à efetividade da justiça brasileira (Port. $n^{\circ} 167 / 2015$, CNJ, art. $2^{\circ}$, incs. I e II).

Para o período 2015-2020, constam, por exemplo, dentre os objetivos estratégicos da Portaria $n^{\circ}$ 167/2015: o aperfeiçoamento da gestão das políticas judiciárias e demais instrumentos de governança do CNJ e do Poder Judiciário; a realização e o incentivo de pesquisas, estudos e diagnósticos sobre o Judiciário; a fomentação de práticas de racionalização dos recursos públicos; o incentivo da disseminação de conhecimento de boas práticas no âmbito do Poder Judiciário; e a promoção dos direitos de cidadania no âmbito do Poder Judiciário, com vistas ao fortalecimento do Estado Democrático de Direito (art. $2^{\circ}, \S 1^{\circ}$, incs. I, II, IV, V e VII).

A Portaria $\mathrm{n}^{\circ} 167 / 2015$ reitera, em seu art. $2^{\circ}$, os componentes da estratégia do CNJ previstos anteriormente na Res. $n^{\circ} 70 / 2009$, que apresenta, dentre os seus componentes, 15 (quinze) objetivos estratégicos distribuídos em 8 (oito) eixos temáticos, dentre os quais: eficiência operacional (garantir a agilidade nos trâmites judiciais e administrativos); acesso à justiça (facilitar o acesso ao sistema de justiça e promover a efetividade no cumprimento das decisões); responsabilidade social (promover a cidadania); alinhamento e integração (garantir o alinhamento estratégico em todas as unidades do Judiciário e fomentar a interação e a troca de experiências entre Tribunais nos planos nacional e internacional); e atuação institucional (fortalecer e harmonizar as relações entre os Poderes, setores e instituições) (Res. $\mathrm{n}^{\circ} 70 / 2009, \mathrm{CNJ}$, art. $\left.1^{\circ}, \mathrm{IV}, a, b, c, d, e\right)$.

Certamente que entre os objetivos estratégicos e entre estes e os eixos temáticos deve existir uma inter-relação e uma coerência, possibilitando o surgimento de condições favoráveis aos "atributos de valor Judiciário para a sociedade". Afinal, é a existência dessas condições que possibilitará a este Poder alcançar a sua pretensão de realizar justiça e ser reconhecido pela sociedade como instrumento efetivo de justiça e paz social (Res. $\mathrm{n}^{\circ} 70 / 2009$, art. $2^{\circ}$, incs. I, II e III).

\footnotetext{
${ }^{3}$ Segundo as diretrizes do "Planejamento Estratégico do Poder Judiciário", coordenado pelo CNJ, os objetivos estratégicos da Port. n० $167 / 2015$ decorrem da ideia de um planejamento estratégico nacional do Poder Judiciário para atender a necessidade de implementação de diretrizes nacionais para a atuação institucional, e visam ao aperfeiçoamento e à modernização dos serviços judiciais, além de uma continuidade administrativa nos tribunais, conforme deliberado no I Encontro Nacional do Judiciário, realizado em 2008, em Brasília, e validado no II Encontro Nacional (BRASIL, 2017c).
} 
Esse alinhamento representa uma das preocupações fundamentais da política judiciária nacional e, consequentemente, do planejamento e da gestão institucional (Res. $n^{\circ} 49 / 2007$; Res. $n^{\circ} 70 / 2009$, CNJ, art. $1^{\circ}$, IV $d$, art. $2^{\circ}, \S \S 1^{\circ}, 2^{\circ}$ e $3^{\circ}$ e art. $6^{\circ}$, caput; Res. $n^{\circ}$ 198/2014, art. $4^{\circ}$, art. 16; Port. $\mathrm{n}^{\circ} 167 / 2015$, art. $2^{\circ}, \S 3^{\circ}$ ) constituindo, com a Lei de Responsabilidade Fiscal (Lei Complementar $n^{\circ} 101$, de 4 de maio de 2000), a base legal sobre a qual os tribunais elaboram e justificam os seus planejamentos estratégicos.

É importante ressaltar, no entanto, que não obstante o fundamento jurídico-legal os planejamentos estratégicos dos tribunais não estão isentos de questionamentos públicos acerca da legalidade ou da moralidade dos seus atos. Apesar de fundada em atos administrativos do CNJ e na Lei de Responsabilidade Fiscal, os planejamentos estratégicos dos tribunais também são questionados no que diz respeito à legalidade e à legitimidade.

O acontece, por exemplo, quando há ameaça iminente aos direitos de cidadania ${ }^{4}$, indicando conflitos entre os objetivos estratégicos do planejamento estratégico nacional e colocando em questão a própria noção de racionalização do sistema judicial como medida de modernização e eficiência (BRASIL, 2015a). Antes, porém, é preciso compreender essa lógica dentro de um quadro mais amplo de reforma judiciária e de democratização da justiça para então analisá-la contextualmente.

\section{A REFORMA DO ESTADO NA AMÉRICA LATINA}

Como os demais países da América Latina, as reformas do Estado no Brasil, desencadeadas a partir do início dos anos 1990, ocorreram juntamente com a inserção do país na economia global e a democratização das instituições políticas. É assim que o objetivo fiscal de redução dos gastos do governo (para garantir sua credibilidade perante os mercados financeiros) associa-se às promessas de mais eficiência no uso dos recursos públicos e de mais qualidade dos serviços prestados à população com novas práticas de

\footnotetext{
${ }^{4} \mathrm{O}$ que aconteceu com a desativação de varas e comarcas no interior do país, a exemplo do Estado da Bahia, cujo Tribunal de Justiça desativou 33 varas e comarcas de entrância inicial, sob a justificativa de que a medida "está alinhada ao que dispõe a Res. no 184/2013, CNJ (TJBA, 2017). A medida causou o protesto de populares e também de instituições como a Associação de Magistrados da Bahia (AMAB) e da Ordem dos Advogados do Brasil (OAB/BA). Para esta última, "o fechamento de comarcas é flagrantemente inconstitucional e ilegal, seja pela violação de direitos individuais e coletivos que acarreta, seja pelo equívoco do veículo utilizado para alcançar pretendida finalidade, porquanto extinção de comarcas por resolução é ato que viola, a um só tempo, as Constituições Federal e Estadual, além da legislação infraconstitucional" (OAB/BA, 2017).
} 
transparência e maior responsabilização dos governos ${ }^{5}$ (LOUREIRO, TEIXEIRA; MORAIS, 2009).

As novas democracias na América Latina - e, consequentemente, as suas reformas estão inseridas neste contexto. As transições políticas dos anos 80 foram produzidas em contextos de severa crise econômica. Desse modo, qualquer análise do processo vivido pelas democracias emergentes da América Latina a partir dos anos 80 deve assumir como dado que a região não é uma realidade isolada no mundo. Mas, constitui um espaço físico e social em que se reproduzem - como em outros momentos de nossa história recente tendências mais vastas que em grande medida transcendem a própria vontade dos atores principais (PUCEIRO, 2010).

O que justifica a convergência das análises dos sistemas judiciais latino-americanos, caracterizados por: a) sua falta de independência, b) sua escassa eficiência e c) sua inacessibilidade. Estas características definem os sistemas judiciais da região antes e depois das transições democráticas e depois das reformas judiciais a partir dos anos 80 . Impulsionados por pressões de organismos internacionais - e em menor medida, de atores locais -, as reformas concentram-se, basicamente, em três objetivos: a) fortalecimento da independência do Poder Judiciário; b) melhoramento da eficiência; e c) diminuição das barreiras de acesso aos tribunais ${ }^{6}$ (SMULOVITZ; URRIBARRI, 2008).

Mas se por um lado o protagonismo dos tribunais - e as próprias transformações do Estado - (TATE; VALLINDER, 1995) não pode ser analisado como se estivesse desvinculado de um contexto global de acontecimentos com configurações econômicas e políticas, por outro, é de fundamental importância reconhecer que uma análise acerca da reforma do sistema judicial no quadro global de reforma do Estado não deve desprezar o fato de que

\footnotetext{
${ }^{5}$ Estudando o processo político de responsabilização dos governantes, O’Donnell (1998) distingue dois tipos de mecanismos de accountability: a) a accountability vertical, no qual os governantes respondem diretamente ao povo, por exemplo, por meio do processo eleitoral; b) accountability horizontal, no qual os governantes respondem indiretamente, mediante controles e mecanismos de prestação de contas entre poderes. Quer dizer, paralelamente ao processo de responsabilização dos governantes pelo voto, as democracias modernas desenvolveram também mecanismos de controle recíprocos dos poderes, por meio dos quais o Legislativo, o Judiciário e outras agências estatais fiscalizam os governantes, de forma continuada, e não apenas episódica, durante os mandatos.

${ }^{6}$ No entanto, devido a uma realidade regional atravessada pelas desigualdades (social, econômica, política, jurídica) e pela violência, verifica-se a necessidade em colocar no mesmo patamar de prioridades as desigualdades e a violência, na medida em que constituem problemas sociais que afetam diretamente a vida das pessoas com impactos negativos no desenvolvimento socioeconômico e político dos países da Região (VANEGAS, 2016).
} 
os países - incluindo aqueles que dividem uma mesma região - podem apresentar problemas e prioridades específicos, como acontece, aliás, em relação às reformas judiciárias e à democratização da justiça na América Latina - não obstante os problemas enfrentados pela justiça e pelas instituições do Estado que se encarregam de administrar a justiça sejam comuns à Região (FRÜHLING, 1997).

\subsection{A Reforma Judiciária na América Latina e no Brasil}

As reformas judiciárias na América Latina têm visado basicamente à modernização e eficiência do Poder Judiciário visando ao melhoramento do acesso ao sistema de justiça especialmente em relação às pessoas que pertencem aos grupos mais vulneráveis da sociedade - e de fortalecimento dos procedimentos judiciais justos e transparentes, de acordo com o Estado Democrático de Direito (CAMPOS, 2011; VARGAS, 2007).

Esta temática assume destaque na América Latina apenas a partir da década de 80, com os movimentos de democratização e o debate público sobre a crise do Judiciário. Esta pauta continuou na agenda dos países ao longo da década de 90 e se estende até os dias atuais, por conta dos reclames dos organismos internacionais - sobretudo, do Banco Mundial -, acerca da construção de uma governança guiada pelo fortalecimento de instituições, após considerar que

A modernização do sistema econômico requer um Estado com capacidade para planejar, controlar e supervisionar as áreas de negócios desregulamentadas, o que, por sua vez, não pode ser realizado se o Judiciário não apresenta uma gestão eficiente da justiça, com capacitação de seus juízes, fortalecimento profissional da magistratura, aperfeiçoamento técnico para intervenção em novas áreas de litigação e para prevenção de crimes, além de capacidade para se adequar a mudanças no direito econômico internacional (SANTOS, 2008, p. 5).

É nesse contexto - de apoio interno e externo - que a política dos países latinoamericanos buscará promover alterações na estrutura do Judiciário. Antes, porém, é preciso afirmar que o destaque que a reforma judiciária alcançou na agenda pública devese ao fato de que os eventos históricos que marcaram a Região, nos anos 70 e 80 (violência política, crimes comuns, reformas econômicas...), reforçaram muitos dos problemas que o Judiciário vinha há tempos enfrentando (apoio e omissão em relação às políticas 
repressivas; justiça criminal presa a um processo criminal ineficiente; níveis elevados de corrupção e desconfiança no Judiciário...) (FRÜHLING, 1997).

É, no entanto, com a transição dos governos civis democraticamente eleitos e a implementação de políticas de livre mercado que virão as maiores contribuições para o interesse atual pela reforma judicial na América Latina, aos quais estão relacionados uma série de fatores em relação aos seus países, dentre os quais: a) a expansão da onda de democratização em países da Região (Equador, Peru, Uruguai...), b) a elevação dos padrões de violência (El Salvador, Colômbia, Brasil...), c) as transformações socioeconômicas instaladas na Região (abertura de mercado, transações financeiras, privatizações...), dentre outros igualmente importantes (FRÜHLING, 1997).

No caso do Brasil, é somente com o fim do autoritarismo e a reorganização constitucional do país, que os analistas se voltam para o estudo e discussão dos aspectos institucionais da nova democracia política brasileira (ARANTES; KERCHE, 1998). A divulgação dos principais problemas do seu sistema judicial (morosidade dos julgamentos, excesso de litigiosidade e falta de acesso à justiça), pelo Diagnóstico do Judiciário (BRASIL, 2004), não só colocou em evidência a "crise do Judiciário" - que também é do Estado e do Direito (LOPES, 2002) -, como justificou, também, a decisão de se implantar definitivamente no país uma política de planejamento estratégico na gestão judiciária com propostas de formulação de políticas públicas voltadas a assegurar modernização e democratização do acesso ao sistema de justiça7 (BRASIL, 2013a).

Visando à aprovação de uma política pública nacional voltada para o tratamento adequado dos conflitos de interesses, o CNJ, aprovou, em 29 de novembro de 2010, a Res. $\mathrm{n}^{\circ} 125$, que institui a Política Judiciária Nacional, destinada a assegurar a todos o direito à solução dos conflitos por meios adequados à sua natureza e peculiaridade, com o objetivo de disseminar a cultura da pacificação social. Perspectiva sob a qual acredita-se efetivar o acesso ao sistema de justiça, desde que os tribunais consigam "redefinir o papel do

\footnotetext{
${ }^{7}$ Com a aprovação da Emenda Constitucional de Reforma do Poder Judiciário (EC n. 45/2004) e a realização do Pacto Republicano (BRASIL, 2013b), houve uma conjugação de esforços voltada para as propostas de alterações legislativas (constitucionais e infraconstitucionais) e, posteriormente, programas governamentais, como a Política de Democratização do Acesso à Justiça (BRASIL, 2013a).
} 
Judiciário na sociedade" de modo a ser percebido como um local onde pessoas buscam e encontram suas soluções - um “centro de harmonização social” (BRASIL, 2015c).

Como parte da estratégia política judiciária, são editados atos normativos (resoluções, portarias) por parte do CNJ, a quem compete o controle da atuação administrativa e financeira dos tribunais, a atribuição de coordenar o planejamento e a gestão estratégica do Poder Judiciário. A finalidade dessa normatização é exatamente atender à exigência de nortear a atuação institucional de todos os seus órgãos, implicando, obrigatoriamente, o alinhamento dos tribunais às diretrizes da política judiciária nacional.

Esse alinhamento corresponde à unicidade do Poder Judiciário e se dá por meio de um sistema de dados baseado em estatísticas e metas. O Sistema de Estatística do Poder Judiciário $^{8}$ foi instituído pelo CNJ e regulamentado pela Res. $\mathrm{n}^{\circ} 15$, de 20 de abril de 2006, que adotou os princípios de publicidade, eficiência, transferência, obrigatoriedade de informação dos dados estatísticos e atualização permanente.

Mas para além da intensificação das funções normativas e administrativas existem também outros temas, igualmente importantes, mas pouco discutidos, como o

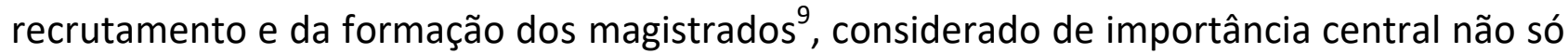
no aumento da eficiência e qualidade do sistema judicial, mas, fundamentalmente, na sua renovação democrática, no sentido de melhor responder aos desafios da sociedade e às expectativas dos cidadãos (SOUSA SANTOS; GOMES, 2011).

O método de escolha dos juízes é uma questão que deve ser enfrentada pela racionalização do sistema judicial, em obediência, inclusive, aos seus objetivos estratégicos (Port. $n^{\circ}$ 167/2015). Sobretudo, pela própria natureza cada vez mais complexa da administração de conflitos (SANTOS, 2008), quando as profissões forenses - em especial a magistratura - sofrem os efeitos dos processos de mudanças consequentes da crise econômica e social que atinge os países provocando mudanças do contexto social da ação

\footnotetext{
${ }^{8}$ Esse sistema analisa os dados com a supervisão de Comissão de Estatística e Gestão Estratégica e a assessoria do Departamento de Pesquisas Judiciárias. Os dados enviados pelos órgãos do Poder Judiciário são obrigatoriamente encaminhados ao CNJ e vinculam a presidência dos tribunais (Res. $n^{\circ} 4 / 2005 \mathrm{c} / \mathrm{c}$ Res. $\mathrm{n}^{\circ}$ 15/2006). Todavia, é importante salientar, a intensificação das funções normativas e administrativas não abrange o processo de racionalização do sistema judicial, constituindo apenas um dos aspectos desse processo.

${ }^{9} \mathrm{O}$ recrutamento e a formação dos magistrados ainda é visto como uma questão histórica delicada e incômoda, decorrente do impacto do Judiciário nas políticas de governo, especialmente nas reformas (ARANTES, 2003) - o que remete, inevitavelmente, à questão da independência judicial nas cortes superiores.
} 
dos tribunais, vistas como motores essenciais para o sucesso das reformas legais e das transformações do sistema judicial (SOUSA SANTOS et al., 1996; GARAPON, 1998).

O que justifica a compreensão de que a racionalização judicial não deve ser desvinculada do contexto social no qual estão inseridas as instituições e seus atores, cujas relações de poder não se submetem à ordem jurídica vigente com seus fundamentos, princípios e regras. Sem uma leitura referenciada pela práxis social, a racionalização judicial será compreendida apenas parcialmente, em seu sentido formal, porquanto afastada da realidade das relações que caracterizam a própria relação Estado-DireitoSociedade no Brasil.

\section{A RACIONALIZAÇÃO DO SISTEMA JUDICIAL}

A racionalização é uma categoria teórica de conceito extremamente complexo e de difícil - ou mesmo impossível (BRUBAKER, 1996). O próprio Weber (2004), considerado o principal teórico da racionalização da era moderna, o percebeu como um conceito fartamente ambíguo ${ }^{10}$, capaz de englobar todo um mundo de sentidos diferentes, de modo que a sua ambiguidade poderia ser equiparada à dos conceitos afins de razão, racionalidade e racionalismo.

Acerca da problemática weberiana da racionalidade e da racionalização, Sell (2012) observa que apesar do tema da racionalização ser atualmente reconhecido por um grande segmento da literatura especializada como uma questão-chave, tal convergência não se verifica quando se busca definir o tratamento weberiano dos conceitos de racionalidade e racionalização.

Esta falta de convergência dos conceitos de racionalidade e racionalização é compreensível, explica o autor, visto que não era intento da sociologia weberiana a elaboração de uma teoria da racionalidade (perspectiva filosófica) em si mesma, pois, esta é apenas condição ou meio para uma tarefa que a engloba e lhe confere sentido: a

\footnotetext{
13 Em seu livro "A ética protestante e o 'espírito' do capitalismo", Weber afirma que "O 'racionalismo' é um conceito histórico que encerra um mundo de contradições [...]" (2004, p. 69). O sentido de racionalização neste artigo está relacionado à aplicação dos meios mais eficientes para se conseguir determinados objetivos, assim como as consequências não pretendidas e negativas de tal aplicação.
} 
explicitação do processo histórico e sociocultural de racionalização ocidental e moderno (perspectiva sociológica). Desse modo,

[...] em Weber, o processo de racionalização não é uma noção que pode ser definida de maneira prévia, como um tipo ideal que precede a análise, pois se trata de um tópico que o pensador desenvolve sempre de forma situada, com um sentido que emerge sempre em ato, quer dizer, embutido no próprio processo de análise. Já em relação à noção de racionalidade, uma análise lexical e epistemológica é possível e [...] não faltam tentativas de sistematizar o sentido dos conceitos de racionalidade nos escritos de Weber (SELL, 2012, p. 156).

A construção teórica em Weber aparece na análise do Estado racional, quando o autor apresenta como "fundamentos da legitimidade de uma dominação": a) a autoridade do costume sagrado por validade imemorável e pela disposição habitual de respeitá-lo (dominação tradicional); b) a autoridade do dom de graça pessoal, extra cotidiano (dominação carismática); e c) a autoridade decorrente da dominação, em virtude de legalidade, da crença na validade de estatutos legais e da competência objetiva, fundamentada em regras racionalmente criadas (dominação legal) (2009, p. 526, grifo no original).

A construção teórica da Sociologia do Estado - e também do Direito ${ }^{14}$-, proposta por Weber (2009) constitui uma valiosa contribuição deste autor, sobretudo no que diz respeito ao Estado racional, às formas de legitimação do poder e à burocracia. Questões que estão direta ou indiretamente relacionadas à discussão deste artigo, cujo alcance teórico, delimitado pelo seu objetivo, se restringe à modernização e à eficiência do sistema judicial visando à simplificação recursal, otimização gerencial e tecnológica ${ }^{11}$ (BRASIL, 2015a) - em outras palavras, a própria racionalização judicial.

\subsection{A racionalização do sistema judicial brasileiro}

A ideia de racionalização do sistema judicial está relacionada a fatores internos e externos, formais e estruturais. É diante dessa coexistência de fatores e de interesses diversos, e às vezes opostos, que o Judiciário tem buscado nortear a sua atuação institucional pautada em um planejamento estratégico nacional que consiste no

\footnotetext{
${ }^{11}$ Esta categorização teórica está, de modo explícito ou implícito, por todo o texto. O que reafirma a interlocução com a Administração Pública que constitui, a nosso ver, um aporte teórico indispensável aos estudos da Administração da Justiça e da Política Judiciária.
} 
desenvolvimento de políticas judiciárias que promovam a efetividade e a unidade do Judiciário, orientadas para valores de justiça e paz social, de modo a ser reconhecido como órgão de excelência em planejamento estratégico, governança e gestão judiciária visando à efetividade da justiça (Port. $n^{\circ}$ 167/2015/CNJ).

Devido ao aumento da demanda judicial, em parte pela ampliação do acesso ao Judiciário, mas, também, pela "negação da justiça" (TAVARES, 2018, p. 52), as soluções gerenciais e de modernização tecnológica tendem a atingir os seus limites de elasticidade, de modo que apenas a mudança de modelo de prestação jurisdicional pode dar à Justiça o dinamismo que os tempos modernos exigem.

É com essa concepção de prestação jurisdicional que a racionalização assume status de condição de eficácia na harmonização das relações sociais ${ }^{12}$ (BRASIL, 2015a), sob o argumento de que o verdadeiro acesso à justiça abrange não somente a prevenção e reparação de direitos, mas, também, a realização de soluções negociadas e o fomento da mobilização da Sociedade, para que possa participar ativamente dos procedimentos de resolução de disputas como de seus resultados (BRASIL, 2015c).

É, portanto, no plano real e não no ideal ${ }^{13}$, de compromissos básicos, que o Judiciário terá que (re)orientar as suas ações para ser reconhecido como "centro de harmonização social" (Res. n 70/2009, CNJ). O que pressupõe readequação (reordenação) e diálogo (reestruturação das relações) institucional. É dizer: uma racionalização. Uma racionalização judicial para adequá-lo aos novos tempos, marcados por um dinamismo e uma complexidade crescentes na administração dos conflitos, de modo a atender aos interesses de todos os segmentos sociais, legitimando-o assim, como órgão de excelência em planejamento estratégico, governança e gestão judiciária visando à efetividade da justiça (Port. $n^{\circ}$ 167/2015/CNJ).

\footnotetext{
${ }^{12}$ Acontece que a ideia de "harmonização social" é bem mais ampla e complexa, assim como não se limita ao abandono de fórmulas exclusivamente positivadas, uma vez que esta ideia de "harmonização social" está vinculada à "ideia de justiça" e vice-versa. Se a intenção é realmente "ser reconhecido pela Sociedade como instrumento efetivo de justiça", o Judiciário terá que assumir o compromisso de "realizar justiça" (Res. $n^{\circ}$ 70/2009, CNJ). Não a "Justiça de classe", que atribui a cada um a sua justiça conforme a sua classe social. Terá que assumir a defesa inegociável da própria justiça, considerando que "em uma sociedade democrática e plural, a Justiça deve ser capaz de atender aos interesses de todos os segmentos" (BARROSO, 2014, p. 9-11).

${ }^{13}$ A respeito da idealização de um Judiciário moderno e eficaz e justo, baseado em um órgão de planejamento estratégico e uma Justiça que atenda aos requisitos básicos de efetividade, celeridade, segurança, modicidade e acessibilidade (BRASIL, 2015a).
} 
É importante compreender, no entanto, que este quadro teórico-metodológico, elaborado pelo próprio Judiciário, a partir de atos normativos como referencial, não confere, por si só, legitimidade à racionalização. É a confrontação entre o quadro teóriconormativo e a contextualização social ${ }^{14}$ que permitirá avaliar a eficácia social dos atos normativos conferindo (ou não) legitimação social à Administração da Justiça e à Política Judiciária (BRASIL, 2016b).

Tal legitimação não se opera, porém, pela simples inserção de tabelas e dados estatísticos, como acontece em relação aos dados coletados pela Semana Nacional da Conciliação (BRASIL, 2018b) - exclusivamente sob o método quantitativo, que não revelam o que realmente acontece nas sessões de conciliação ${ }^{15}$. Quando, na verdade, são exatamente as rotinas e as práticas judiciárias que permitem auferir eficácia e conferir legitimidade social à racionalização. Esta realidade indica que as rotinas e as práticas judiciárias representam não só um desafio para a Administração da Justiça e a Política Judiciária, como também, uma das causas do abismo entre o campo dogmático (abstrato) e o campo empírico (concreto).

\section{DESAFIOS E PERSPECTIVAS}

Os desafios e as perspectivas do Judiciário estão relacionados ao seu protagonismo social e político nas sociedades contemporâneas (SOUSA SANTOS et al., 1996). No caso dos países latino-americanos o Judiciário nunca foi tema importante em matéria de reforma. Inicialmente cabia ao juiz, apenas e tão-somente, a figura inanimada de aplicador da letra

\footnotetext{
${ }^{14}$ Para atender a essa realidade foi concebida pelo Departamento de Pesquisas Judiciárias do Conselho Nacional de Justiça (DPJ/CNJ) a série "Justiça Pesquisa", a partir de dois eixos estruturantes complementares entre si: a) "Direitos e garantias fundamentais" e b) "Políticas públicas do Poder Judiciário". O eixo "Direitos e garantias fundamentais" enfoca aspectos relacionados à realização de liberdades constitucionais a partir do critério funcional de ampliação da efetiva proteção a essas prerrogativas constitucionais. E o eixo "Políticas públicas do Poder Judiciário", por sua vez, enfoca aspectos institucionais de planejamento, gestão de fiscalização de políticas judiciárias a partir de ações e programas que contribuam para o fortalecimento da cidadania e da democracia. Os dois eixos estão vinculados às abordagens empíricas dos temas, conforme projetos publicados a respeito. A perspectiva doutrinária ou teórica deve atuar como marco para construção e verificação de hipóteses, assim como para definição dos problemas, de modo que as pesquisas não podem ser exclusivamente teóricas ou doutrinárias (BRASIL, 2015b).

${ }^{15}$ Pesquisas empíricas realizadas em tribunais do Rio de Janeiro e da Bahia, por exemplo, apontam para a existência: a) de divergências na apropriação judicial dos meios alternativos, onde métodos consensuais ganham contornos e significados próprios, e b) de relações institucionais que assumem um papel determinante, às vezes, contrárias às próprias diretrizes da Res. nº125/2010, CNJ (AMORIM; BAPTISTA, 2013; TAVARES, 2014).
} 
da lei, de modo semelhante ao modelo europeu (SUTIL, 2000). As reformas do Estado na América Latina são desencadeadas apenas a partir do início dos anos 1990 e ocorreram juntamente com a inserção do país na economia global e a democratização das instituições políticas.

As transformações do Judiciário se inserem, portanto, nas transformações do Estado que, por sua vez, estão relacionadas a um contexto global de acontecimentos com configurações econômicas e políticas (TATE; VALLINDER, 1995), quando diversos países foram afetados e houve um aprofundamento em relação à mudança do ambiente social da ação dos tribunais (SOUSA SANTOS; GOMES, 2011). É nesse contexto dessas transformações sociais, políticas e econômicas que os países latino-americanos buscarão promover alterações na estrutura do Judiciário.

No caso do Brasil é importante acrescentar que o contexto social pós-constituinte não teve apenas a dívida social como realidade a ser enfrentada pelo Estado - e pelo Direito - com a Constituição de 1988. Teve que enfrentar, também, a falta de representatividade do sistema político, decorrente da incapacidade dos seus partidos políticos de formar quadros com compromissos programáticos e ideológicos baseados em interesses comuns, e os problemas de eficiência do sistema econômico, no plano público, revelado pela incapacidade de implementar políticas públicas e, especialmente, pela sua impotência decorrente de uma inflação crescente e agravada pela dívida externa, e no plano privado, por um ajuste estrutural que desorganiza o processo de industrialização, mantém a estagnação econômica e inibe a produção e o consumo.

Todas essas questões - muitas das quais decorrentes das omissões do Executivo e do Legislativo - são transferidas para o Judiciário que, sob críticas dos seus principais problemas (morosidade dos julgamentos, excesso de litigiosidade e falta de acesso à justiça) (BRASIL, 2004), será forçado a tomar a decisão de implantar definitivamente uma política de planejamento estratégico na gestão judiciária com propostas de formulação de políticas públicas voltadas a assegurar modernização e democratização do acesso ao sistema de justiça quando, como parte do planejamento estratégico, serão elaboradas medidas como atos normativos e políticas judiciárias emanadas pelo CNJ e fundamentadas na estratégia Nacional do Poder Judiciário (Res. n 198/2014, CNJ, art. 11). 
Para dar conta dessas medidas o Judiciário criou, dentro do Planejamento e Gestão Estratégica, uma Rede de Governança Colaborativa (Port. $n^{\circ} 138 / 2013$ ), coordenada pelo CNJ, e que tem como competência apresentar propostas de aperfeiçoamento da “Estratégia Judiciário 2020" (BRASIL, 2017a), bem como auxiliar a execução, o monitoramento dos trabalhos e a divulgação dos resultados (Res. n 198/2014, CNJ, arts. 10 e 11). Uma das deliberações formuladas pela Rede de Governança Colaborativa está diz respeito aos "Macrodesafios do Judiciário para o sexênio 2015-2020"16 ("Estratégia Judiciário 2020"), conforme aprovação no VII Encontro Nacional do Judiciário, realizado em 2013 (BRASIL, 2015d).

É a partir dessa articulação temática, observando as tendências atuais (quadro real) e o cenário desejado (quadro ideal), que o Judiciário norteará a sua atuação institucional em busca não apenas uma justiça mais acessível, mas, também, uma maior racionalização do sistema judicial. Evidentemente que existem temas em que o enfrentamento deverá ser realizado por meio uma ação conjunta do Judiciário (CNJ, STF, TJ) e dos demais Poderes (Executivo e Legislativo), como acontece, por exemplo, em relação ao aperfeiçoamento da gestão da justiça criminal, cujas providências requerem a adoção de medidas preventivas à criminalidade e ao aprimoramento do sistema criminal, mas, também investimentos em relação ao sistema penitenciário, cuja "situação calamitosa" há tempos é por todos conhecida, inclusive, pelo próprio Judiciário (BRASIL, 2018c, 2018d).

Em auditoria do Tribunal de Contas da União (TCU) no sistema prisional brasileiro, constatou-se que 59\% dos 17 Estados fiscalizados não haviam calculado o custo mensal do preso nos últimos três anos. Além disso, 11 das 18 Unidades da Federação - incluído o Distrito Federal, portanto, 61\% - enfrentaram algum tipo de rebelião de outubro de 2016 a maio de 2017. Foi verificado, também, que a maior parte das rebeliões, nesse período,

\footnotetext{
${ }^{16}$ Os "Macrodesafios" que vão nortear as atividades do Judiciário de 2015 até 2020 estão divididos em três grandes temáticas: Sociedade, Processos internos e Recursos, que se subdividem em diversos temas relacionados à efetividade jurisdicional e à plena garantia de direitos. Mas para além de uma efetiva prestação jurisdicional em suas dimensões (acesso à justiça, duração do processo e custo), garantindo, no plano concreto, os direitos de cidadania em sua múltipla manifestação social (cidadão-administrado; cidadão-eleitor, cidadão-trabalhador-produtor; cidadão-consumidor; cidadão-contribuinte...), o Judiciário terá que enfrentar temas como o aperfeiçoamento da gestão da justiça criminal; a gestão das demandas repetitivas e dos grandes litigantes; o impulso às execuções fiscais, cíveis e trabalhistas; o combate à corrupção e à improbidade administrativa; o aperfeiçoamento e gestão de custos e a instituição da governança judiciária, dentre outros (Anexo da Res. n 198/2014, CNJ).
} 
ocorreu em estabelecimentos com déficit de vagas: 18 das 23 unidades prisionais que tiveram registro de rebeliões. Ou seja, $78 \%$ dos casos de rebelião se deram em presídios com excesso de lotação (TCU, 2018).

Diante dos últimos episódios envolvendo mortes, rebeliões e fugas nas penitenciárias, não se deve ignorar que, se por um lado, a "crise no sistema penitenciário brasileiro" (BRASIL, 2018c) aponta para "a importância do fortalecimento dos Grupos de Monitoramento e Fiscalização do Sistema Carcerário (GMFs)" (BRASIL, 2018e), por outro, também pode ser indicativa de um quadro social cada vez mais problemático em termos de oportunidades, injustiças e marginalização e cujas consequências se tornam cada vez mais evidentes com o mito do Estado mínimo debilitando o Estado Social e exaltando o Estado Penal (DORNELLES, 2008).

Igualmente importante é a gestão de demandas repetitivas e dos grandes litigantes, sobretudo em tempos de "desjudicialização" e "descongestionamento do Poder Judiciário"17 (Anexo Por. n 198/2014, CNJ). Em um estudo divulgado pelo CNJ ("Demandas repetitivas e a morosidade na justiça cível brasileira"), com base nos resultados de pesquisa feita pelo Departamento de Pesquisas Judiciárias (DPJ/CNJ), junto a todos os tribunais do país, os números indicaram que a Justiça trabalha para poucas pessoas - a propósito, estima-se que os cem maiores litigantes correspondam a $20 \%$ dos processos no país (BRASIL, 2011a).

O setor público (federal, estadual e municipal), os bancos e a telefonia representaram aproximadamente $35,5 \%$ do total de processos ingressados em 2011 . Com relação ao total de processos ingressados de cada Justiça, esse percentual quase atinge o patamar de 32,5\% na Justiça Estadual; 93,5\% na Justiça Federal e 5,5\% na Justiça do Trabalho. Os bancos e o setor público (municipal, estadual e federal), apresentaram o maior percentual de processos novos em relação ao total ingressado em 2011 da Justiça Estadual de 1 o Grau, com aproximadamente $34,4 \%$ do total de processos (BRASIL, 2012b).

O setor público federal e os bancos apresentaram os maiores percentuais de processos em relação ao total ingressado no período, com, respectivamente, 68,8\% e

\footnotetext{
17 Este é um problema conhecido antes mesmo de 2004, quando o Diagnóstico do Judiciário destacou os principais problemas do mau funcionamento da justiça, apontando, inclusive, o Estado como o maior litigante (TAVARES, 2014).
} 
13,4\%, no 1 음 Grau, e 92,3\% e 7,2\%, nos Juizados Especiais (JEC). Do total de processos dos 100 maiores litigantes da Justiça Federal, 62\% referem-se ao polo passivo e $38 \%$ ao ativo, enquanto que nos Juizados Especiais $99,8 \%$ são referentes ao polo passivo (BRASIL, 2012b).

Como apontam os estudos, "predomina uma realidade de excessiva concentração de demanda por esses serviços. Ou seja, no Brasil, poucos usam muito o Poder Judiciário ao passo que muitos ainda o utilizam pouco" (BRASIL, 2011a, p. 21). O próprio estudo realizado pelo CNJ, a respeito dos "Cem maiores litigantes" nos tribunais do País, aponta para essa concentração de demandas ${ }^{18}$ (BRASIL, 2012b), colocando em questão a "crise de hiperlitigiosidade" (BARROSO, 2014, p. 1).

Não menos importante é a gestão de custos, que sobreleva em tempos de discussão sobre políticas de redução da injustiça social e das desigualdades estruturais no país (CAMPELLO, 2017), exatamente onde a Administração Pública Federal - incluindo Executivo, Legislativo e Judiciário federais - gasta mensalmente $\mathrm{R} \$ 3,47$ bilhões com 0 pagamento de funcionários em cargos de confiança e comissionados. Um valor que representa $35 \%$ de toda a folha de pagamento do funcionalismo público na esfera federal, que é de $\mathrm{R} \$ 9,6$ bilhões mensais (TCU, 2016a).

Em relação à origem do vínculo de pessoas com cargos em comissão, 60\% dessas funções são ocupadas por servidores efetivos, enquanto os demais são ocupados por pessoas sem vínculo com a Administração. Quando esta análise é feita por Poder, o Legislativo apresenta $97 \%$ de servidores sem vínculo com a Administração e o Judiciário e o Executivo apresentam a maioria dos cargos em comissão ocupados por servidores do próprio quadro, nos percentuais de $83 \%$ e $64 \%$, respectivamente (TCU, 2016a).

Em 2013, o TCU realizou um levantamento sobre a situação da governança do setor público brasileiro em âmbito nacional a fim de propiciar o melhor aproveitamento na

\footnotetext{
${ }^{18} \mathrm{Em}$ estudos relativos ao ano de 2011, o Instituto Nacional do Seguro Social (INSS) constava como o maior litigante nacional, correspondendo a 22,3\% das demandas dos cem maiores litigantes nacionais, seguido pela Caixa Econômica Federal, com 8,5\%, e pela Fazenda Nacional, com 7,4\%. Na Justiça Estadual, o Estado do Rio Grande do Sul constava como o maior litigante, com 7,7\% das demandas, seguido pelo Banco do Brasil e pelo Banco Bradesco. Já na esfera da Justiça do Trabalho, a União era a maior litigante, com 16,7\% das demandas. No mesmo período, o setor público (estadual, federal e municipal), bancos e telefonias representavam, por sua vez, $95 \%$ do total de processos dos cem maiores litigantes nacionais (BRASIL, 2011b, 2012b).
} 
aplicação de recursos públicos, no qual foram contemplados os órgãos governantes superiores, responsáveis por normatizar e fiscalizar a gestão de pessoas nos segmentos da Administração Pública Federal, como o CNJ - em relação aos órgãos do Poder Judiciário. E neste levantamento o TCU identificou deficiências nos sistemas de governança e gestão de pessoas da maioria das organizações avaliadas, cujo "resultado revelou um cenário preocupante, ainda mais quando considerado o capital humano como principal ativo da organização" (TCU, 2016b).

Por fim, há uma questão da qual Judiciário não poderá fugir ao enfrentamento e que diz respeito aos benefícios (auxílio-moradia, saúde, alimentação...) pagos aos membros da magistratura e aos servidores a qualquer título, colaboradores e colaboradores eventuais, visto por magistrados como "ajuda de custo" (GENTILE, 2018), mas, considerado, por uma parte da Sociedade como "privilégios", "penduricalhos" (GARCIA, 2018) - mas, cujo valor, em alguns casos, ultrapassa o salário de docentes do magistério superior em universidades públicas do país.

O argumento de que o benefício configura um "direito" (GENTILE, 2018), porquanto “previsto em lei" (GARCIA, 2018), coloca em questão o aspecto jurídico-legal da questão ${ }^{19}$, à medida que os benefícios concedidos a juízes estaduais pelo país revelam um quadro de disparidade e distorções nas modalidades e valores de auxílios recebidos (LINHARES; FLECK; MATTOSO, 2018), mas, também, ético-moral, considerando o contexto de desigualdade social do país (MAIA, 2017).

A atitude de indiferença à realidade social - que no caso dos benefícios é justificado simplesmente pela "legalidade da lei" - é uma das causas que fazem com que o Judiciário seja visto como um Poder distante da sociedade brasileira. Uma imagem que contrasta com o discurso do próprio Judiciário acerca da pretensão de ser percebido "centro de harmonização social" (Res. n 70/2009, CNJ) (BRASIL, 2018f).

\footnotetext{
${ }^{19} \mathrm{O}$ aspecto jurídico-legal constitui, na verdade, o pano de fundo da questão. O que se percebe aqui é a presença de pensamento legalista bastante arraigado em nossa cultura jurídica e que é bem diferente da legalidade em si. O pensamento legalista evidencia uma concepção deturpada da legalidade visto que não considera a finalidade para a qual foi proposta a lei - e nesse sentido contraria a própria lei, visto que "Na aplicação da lei, o juiz atenderá aos fins sociais a que ela se dirige e às exigências do bem comum" (LINDB, art. $5^{\circ}$ ) - e muito menos o contexto social de aplicação dessa lei. O argumento de justificação dos benefícios baseado apenas previsão da lei representa este pensamento, na medida em que se justifica pela simples existência formal da lei, cujas consequências sociais não importam.
} 
Evidentemente que estes temas representam apenas uma parte dos "Macrodesafios" do Judiciário, voltados para aqueles temas que requerem uma ação conjunta do Judiciário e dos demais Poderes. No entanto, são bastante representativos da situação que coloca de um lado, o quadro normativo (ideal), e de outro, o contexto social (real), o que marcou profundamente a relação Estado, Direito e Sociedade no Brasil.

\section{CONSIDERAÇÕES FINAIS}

À medida que a necessidade de implementação de diretrizes nacionais exigiu a racionalização judicial para nortear a atuação institucional, fez também com que o Judiciário incorporasse à sua agenda categorias até então desconhecidas de suas práticas cotidianas. Em contrapartida houve um incremento notável de suas funções "secundárias" de normatização e administração na tentativa de aperfeiçoar a prestação dos serviços judiciários. Essa nova realidade insere a racionalização do sistema judicial em um contexto complexo, dinâmico e de intensas transformações, onde os atores não só disputam espaços como ganham diferentes papéis, impondo não somente novas demandas, mas, também, novas relações.

É exatamente neste contexto que a racionalização do sistema de justiça aparece vinculada ao contexto de reordenação institucional e de reestruturação da relação EstadoDireito-Sociedade, justificando a necessidade de compreensão da inter-relação de fatores de ordem social, econômica, política, para verificar como aqueles processos ensejam mudanças estruturais e procedimentais, impondo um rearranjo dos papéis e das relações institucionais, conforme disposto na Constituição de 1988 - e, posteriormente, em legislações específicas.

Com o novo modelo institucional da Constituição de 1988 os significados de reordenação institucional e de reestruturação das relações entre Estado e Sociedade assumem importância - em sentido formal e material -, impondo mudanças estruturais e procedimentais às instituições democráticas e trazendo inovações significativas para as instituições de justiça (Judiciário, Ministério Público, Defensoria Pública, polícias...), as instituições políticas (Poder Executivo e Poder Legislativo) e as instituições sociais de modo geral (Estado, Sociedade, Família...), especialmente no plano das responsabilidades. 
Como visto, a compreensão dessa realidade, que coloca em questão a atuação do Direito nos espaços privilegiados de poder da relação Estado, Direito e Sociedade, é fundamental para a racionalização do sistema judicial no que diz respeito aos seus objetivos estratégicos mas, também, para alcançar o compromisso de realizar justiça e, consequentemente, de ser reconhecido instrumento efetivo de justiça, equidade e paz social.

O que remete aos "Macrodesafios do Judiciário", cujas respostas requerem uma ação conjunta do Judiciário e dos demais Poderes e que coloca em questão o próprio comportamento institucional frente aos desafios sociais. Os temas analisados (aperfeiçoamento da gestão da justiça criminal; gestão das demandas repetitivas e dos grandes litigantes; gestão de custos; moralidade administrativa...) são bastante representativos da situação que coloca de um lado, o quadro normativo (ideal), e de outro, o contexto social (real), reportando à configuração institucional histórica que marcou profundamente a relação Estado, Direito e Sociedade no Brasil.

Como se tem afirmado, romper os espaços, as estruturas e as relações de poder, não é fácil, sobretudo quando a formação e a relação institucional molda costumes e comportamentos. Mas esta é apenas uma das razões pelas quais a racionalização do sistema judicial não pode ser interpretada apenas como um quadro teórico-metodológico, mas, como um processo social, no qual instituições e atores disputam espaços e ganham diferentes papéis.

Compreendemos que o enfrentamento desse processo social pressupõe readequação (reordenação) e diálogo (reestruturação das relações) institucional, sobretudo da relação Estado, Direito e Sociedade, para que a racionalização do sistema judicial represente os interesses de todos os segmentos, conforme os fundamentos, princípios e regras do Estado Democrático de Direito.

Importante ressaltar, no entanto, que as dificuldades e os desafios com os quais têm se defrontado o Judiciário não são apenas de ordem teórico-metodológica, mas, determinados por um quadro social, político e econômico complexo, dinâmico e de intensas transformações, onde os atores disputam espaços e ganham diferentes papéis. Um contexto que coloca novos desafios teóricos e metodológicos na agenda de pesquisa 
das ciências sociais, das instituições estatais, às organizações da sociedade civil e às relações informais, da escala supranacional ao espaço local.

O enfrentamento desse contexto pressupõe readequação (reordenação) e diálogo (reestruturação das relações institucionais) institucional, no caso, da própria relação Estado-Direito-Sociedade, para que a racionalização do sistema judicial represente os interesses de todos os segmentos. É de acordo com essa compreensão que a racionalização deve ser articulada como modernização e eficiência do sistema judicial e como condição de eficácia na harmonização das relações sociais, desenvolvendo políticas judiciárias que promovam a efetividade do Judiciário, orientadas por valores de justiça e paz social.

\section{REFERÊNCIAS}

ALMEIDA, Maria Hermínia Tavares de. Continuando a mudar: os desafios da reforma social. São Paulo: USP, 2003.

AMORIM, Maria Stella de; BAPTISTA, Bárbara Gomes Lupetti. Mediação e conciliação revisitadas. Meios alternativos de administração de conflitos no direito nos tribunais brasileiros. Niterói, 2013. Disponível em: http://www.uff.br/ineac. Acesso em: 20 fev. 2013.

ARANTES, Rogério Bastos. Consensos e dissensos na reforma constitucional do Judiciário. In: Armando Castelar Pinheiro (org.). Reforma do Judiciário: problemas, desafios, perspectivas. Rio de Janeiro: Booklink, 2003. p. 120-137.

; KERCHE, Fábio. Judiciário e democracia no Brasil. Novos Estudos CEBRAP, São Paulo, n. 54, p. 27-41, jul. 1999.

BARROSO, Luís Roberto. Por uma cultura de menor litigiosidade. Revista Diálogos sobre Justiça. Secretaria de Reforma do Judiciário. Centro de Estudos sobre o Sistema de Justiça, n. 2, maio/ago. 2014, Brasília, p. 09-15.

BOURDIEU, Pierre. A economia das trocas simbólicas. Tradução de Sérgio Miceli. São Paulo: Perspectiva, 2007.

BRUBAKER, William Rogers. Racionalização. In: OUTHWAITE, William; BOTTOMORE, Tom (org.). Dicionário do pensamento social do Século XX. Tradução de Eduardo Francisco Alves e Álvaro Cabral. Rio de Janeiro: Jorge Zahar Editor, 1996. p. 641-642. 
CAMPELLO, Tereza (coord.). Faces da desigualdade no Brasil. Um olhar sobre os que ficam para trás. CLACSO; FLACSO; Agenda Igualdade, 2017.

CAMPOS, Santiago Pereira (coord.). Modernización de la justicia civil. Montevideo: Universidad de Montevideo, 2011.

DORNELLES, João Ricardo Wanderley. Conflito e segurança: entre pombos e falcões. Rio de Janeiro: Lumen Juris, 2008.

FRÜHLING, Hugo. Reforma judiciária e democratização na América Latina. Revista do Serviço Público, v. 48, n. 1, p. 90-125, jan./abr. 1997.

GARAPON, Antoine. 0 juiz e a democracia: guardião das promessas. Lisboa: Instituto Piaget, 1998.

GARCIA, Euclides Lucas. Judiciário: de direitos a privilégios. Gazeta do Povo, set. 2014.

Seção Vida Pública. Disponível em: http://www.gazetadopovo.com.br/vidapublica/judiciario-de-direitos-a-privilegios-edvmbi7kn3sbjmbyi1a2gf2oe. Acesso em: 15 jan. 2018.

GENTILE, Rogério. Auxílio-moradia para juiz é direito, não privilégio, diz presidente de entidade. Folha de São Paulo, fev. 2018. Seção Poder. Disponível em: https://www1.folha.uol.com.br/poder/2018/02/auxilio-moradia-para-juiz-e-direito-naoprivilegio-diz-presidente-de-entidade.shtml. Acesso em: 18 fev. 2018.

LINHARES, Carolina; FLECK, Isabel; MATTOSO, Camila; BRAGON, Ranier. Benefícios a juízes nos Estados têm disparidades e distorções. Folha de São Paulo, fev. 2018. Seção Poder. Disponível em: https://www1.folha.uol.com.br/poder/2018/02/beneficios-a-juizes-nosestados-tem-disparidades-e-distorcoes.shtml. Acesso em: 18 fev. 2018.

LOPES, José Reinaldo de Lima. Crise da norma jurídica e a reforma do Judiciário. In: FARIA, José Eduardo (org.). Direitos humanos, direitos sociais e justiça. 1. ed. 3. tir. São Paulo: Malheiros, 2002, p. 68-93.

LOUREIRO, Maria Rita; TEIXEIRA, Marco Antonio; MORAES, Tiago Cacique. Democratização e reforma do Estado: o desenvolvimento institucional dos tribunais de contas no Brasil recente. Revista de Administração Pública. Rio de Janeiro, n. 43, p.779-772, jul./ago. 2009. LOUREIRO, Maria Rita; ABRUCIO, Fernando Luiz. Política e reformas fiscais no Brasil recente. Revista de Economia Política, São Paulo, v. 24, p. 50-72, 2004.

MAIA, Katia (coord.). A distância que nos une. Um retrato das desigualdades brasileiras. OXFAM, 2017.

O'DONNELL, Guillermo. Accountability horizontal e novas poliarquias. Revista Lua Nova, São Paulo, n. 44, 1998.

PUCEIRO, Zuleta. O processo de globalização e a reforma do Estado. In: FARIA, José Eduardo. Direito e globalização econômica: implicações e perspectivas. 1. ed. 3. tir. São Paulo: Malheiros, 2010. p. 105-126.

SADEK, Maria Tereza. Magistrados: uma imagem em movimento. Rio de Janeiro: FGV, 2006. 
SADEK, Maria Tereza. Judiciário: mudanças e reformas. Estudos Avançados, São Paulo, v. 18, n. 51, p. 79-101, ago. 2004.

SADEK, Maria Tereza (org.). Estudos sobre o sistema de justiça. In: MICELI, Sérgio. 0 que ler na ciência social brasileira. São Paulo: Sumaré, 2002, v. IV, p. 233-265.

SANTOS, Élida de Oliveira Lauris dos. A independência judicial na reforma do judiciário brasileiro. In: VI Congresso Português de Sociologia. Mundos sociais: saberes e práticas. Lisboa, 2008.

SELL, Carlos Eduardo. Sociologia clássica: Marx, Durkheim e Weber. 2. ed. Petrópolis: Vozes, 2010.

SELL, Carlos Eduardo. Racionalidade e racionalização em Max Weber. Revista Brasileira de Ciências Sociais, São Paulo, vol. 27, n. 79, p. 153-172, jun. 2012.

SOUSA SANTOS, Boaventura de (Dir. Cient.); GOMES, Conceição (coord.). 0 sistema judicial e os desafios da complexidade social: novos caminhos para o recrutamento e a formação de magistrados. Coimbra: Observatório Permanente da Justiça Portuguesa; Centro de Estudos Sociais da Universidade de Coimbra, 2011.

SOUSA SANTOS, Boaventura de; PEDROSO, João; MARQUES, Maria Manuel Leitão; FERREIRA, Pedro. Os tribunais nas sociedades contemporâneas: o caso português. Porto: Afrontamento/CES/CEJ, 1996.

SUTIL, Jorge Correa. Reformas judiciárias na América Latina: boas notícias para os não privilegiados. In: O’DONNELL, Guillermo et al. (org.). Democracia, violência e injustiça: o não-Estado de Direito na América Latina. São Paulo: Paz e Terra, 2000.

SMULOVITZ, Catalina; URRIBARRI, Daniela. Poderes judiciales en América Latina: entre la administración de aspiraciones y la administración del derecho. San Pablo/Brasil; Santiago de Chile: iFHC/CIEPLAN, 2008.

TATE, Neal C.; VALLINDER, Torbjörn (org.). The global expansion of judicial power. New York: New York University Press, 1995.

TAVARES, Luiz Claudio Assis. Poder Judiciário: reforma e política de acesso à justiça. Porto: Juruá, 2018.

VANEGAS, Farid Samir Benavides et al. La reforma a la justicia en América Latina: las lecciones aprendidas. Bogotá: Friedrich Ebert Stiftung: Programa de Cooperación en Seguridad Regional, 2016.

VARGAS, Juan Enrique (ed.). Nueva justicia civil para Latinoamérica: aportes para la reforma. Santiago de Chile: CEJA, 2007.

WEBER, Max. Economia e sociedade. Fundamentos da sociologia compreensiva. Tradução de Regis Barbosa e Karen Elsabe Barbosa. Brasília: Editora da UnB, 2009. (v. 2).

WEBER, Max. A ética protestante e o "espírito" do capitalismo. Tradução de José Marcos Mariani de Macedo. 6 reimp. São Paulo: Companhia das Letras, 2004. 


\section{Sites e documentos}

BANCO MUNDIAL. O Setor Judiciário na América Latina e no Caribe. Elementos para reforma. Documento Técnico no 319. Tradução de Sandro Eduardo Sardá. Washington, DC: Banco Mundial, 1996.

BRASIL. Conselho Nacional de Justiça [CNJ]. Sistema Nacional de Capacitação Judicial. Disponível em: http://www.cnj.jus.br/formacao-e-capacitacao/sistema-nacional-decapacitacao-judicial. Acesso em: 10 jan. 2018a.

BRASIL. Conselho Nacional de Justiça. Semana Nacional da Conciliação. Resultados. Disponível em http://www.cnj.jus.br/programas-e-acoes/conciliacao-e-mediacao-portalda-conciliacao/semana-nacional-de-conciliacao/resultados. Acesso em: 29 jul. 2018b.

BRASIL. Conselho Nacional de Justiça. Relatório do levantamento de presos provisórios no Brasil. Disponível em: http://www.cnj.jus.br/noticias/cni/84374-veja-a-integra-dolevantamento-dos-presos-provisorios-no-brasil. Acesso em: 15 jan. 2018c.

BRASIL. Conselho Nacional de Justiça. Crise dos presídios: as providências do CNJ. Disponível em: http://www.cnj.jus.br/noticias/cnj/84618-crise-dos-presidios-no-norte-cnjesta-atento. Acesso em: 15 jan. 2018d.

BRASIL. Conselho Nacional de Justiça. Rebeliões mostram necessidade de mais fiscalização nos presídios. Disponível em: http://www.cnj.jus.br/noticias/cnj/84960fortalecimento-dos-gmfs-aprimora-atuacao-dos-magistrados. Acesso em: 15 jan. $2018 \mathrm{e}$.

BRASIL. Conselho Nacional de Justiça. Críticas e elogios: como a imprensa vê o Judiciário. Disponível em: http://www.cnj.jus.br/noticias/cnj/85371-criticas-e-elogios-como-aimprensa-ve-o-poder-judiciario. Acesso em: 10 jan. $2018 \mathrm{f}$.

BRASIL. Conselho Nacional de Justiça. Estratégia Judiciário 2020. Disponível em http://www.cnj.jus.br/files/conteudo/destaques/arquivo/2015. Acesso em: 09 mar. $2017 a$.

BRASIL. Conselho Nacional de Justiça. I Encontro Nacional do Judiciário. Disponível em: http://www.cnj.jus.br/gestao-e-planejamento/encontros-nacionais/1-encontro-nacionaldo-judiciario. Acesso em: 02 mar. 2017b.

BRASIL. Conselho Nacional de Justiça. II Encontro Nacional do Judiciário. Disponível em: http://www.cnj.jus.br/gestao-e-planejamento/encontros-nacionais/2-encontro-nacionaldo-judiciario. Acesso em: 09 mar. 2017c.

BRASIL. Conselho Nacional de Justiça. Manifestação do Ministro Gilmar Mendes no encerramento do II Encontro Nacional do Judiciário. Disponível em: http://www.cnj.jus.br/gestao-e-planejamento/encontros-nacionais/2-encontro-nacionaldo-judiciario. Acesso em: 09 mar. 2017d.

BRASIL. Conselho Nacional de Justiça. Rede de Governança Colaborativa do Poder Judiciário. Disponível em: http://www.cnj.jus.br/gestao-e-planejamento/rede-degovernanca-colaborativa-do-poder-judiciario. Acesso em: 24 maio 2017 e.

BRASIL. Conselho Nacional de Justiça. O CNJ e a racionalização judicial. Disponível em: http://www.cnj.jus.br/agencia-cnj-de-noticias/artigos/13351-o-cnj-e-a-racionalizacaojudicial. Acesso em: 04 mar. 2015a. 
BRASIL. Conselho Nacional de Justiça. Justiça Pesquisa. Disponível em: http://www.cnj.jus.br/pesquisas-judiciarias/justica-pesquisa. Acesso em: 27 jul. $2015 b$.

BRASIL. Conselho Nacional de Justiça. Guia de Conciliação e Mediação Judicial: orientação para instalação de CEJUSCs. Brasília, 2015c.

BRASIL. Conselho Nacional de Justiça. VII Encontro Nacional do Judiciário. Disponível em: http://www.cnj.jus.br/gestao-e-planejamento/encontros-nacionais/7-encontro-nacionaldo-judiciario. Acesso em: 25 out. 2015d.

BRASIL. Conselho Nacional de Justiça. Portaria $n^{\circ}$ 167, de 15 de dezembro de 2015. Institui o Plano Estratégico do Conselho Nacional de Justiça para o período de 2015-2020.

BRASIL. Conselho Nacional de Justiça. IV Encontro Nacional do Poder Judiciário. Disponível em: $\quad$ http://www.cnj.jus.br/gestao-e-planejamento/encontros-nacionais/4-encontronacional-do-poder-judiciario. Acesso em: 18 maio 2013.

BRASIL. Conselho Nacional de Justiça. Relatório Final das Metas Nacionais do Poder Judiciário 2011. Ed. rev. e atual. Brasília, 2012a.

BRASIL. Conselho Nacional de Justiça. 100 maiores litigantes - 2012. Brasília, DF, $2012 b$.

BRASIL. Conselho Nacional de Justiça. Demandas repetitivas e a morosidade na justiça cível brasileira. Brasília, 2011a.

BRASIL. Conselho Nacional de Justiça. INSS lidera número de litígios na Justiça. Brasília, 2011b.

BRASIL. Conselho Nacional de Justiça. Portaria $n^{\circ}$ 167, de 15 de dezembro de 2015. Institui o Plano Estratégico do Conselho Nacional de Justiça para o período de 2015-2010.

BRASIL. Conselho Nacional de Justiça. Resolução $n^{\circ} 198$, de $1^{\circ}$ de julho de 2014 . Dispõe sobre o Planejamento e a Gestão Estratégica no âmbito do Poder Judiciário e dá outras providências.

BRASIL. Conselho Nacional de Justiça. Portaria $n^{\circ}$ 138, de 23 de agosto de 2013. Institui Rede de Governança Colaborativa do Poder Judiciário.

BRASIL. Conselho Nacional de Justiça. Resolução $n^{\circ}$ 70, de 18 de março de 2009. Dispõe sobre o Planejamento e a Gestão Estratégica no âmbito do Poder Judiciário e dá outras providências.

BRASIL. Conselho Nacional de Justiça. Resolução $n^{\circ}$ 49, de 18 de dezembro de 2007. Dispõe sobre a organização de Núcleo de Estatística e Gestão Estratégica nos órgãos do Poder Judiciário.

BRASIL. Ministério da Justiça [MJ]. Reforma do Judiciário. Acesso à Justiça. Disponível em: http://portal.mi.gov.br. Acesso em: 19 jun. $2013 a$.

BRASIL. Ministério da Justiça. Reforma do Judiciário. Pacto Republicano. Disponível em: http://portal.mi.gov.br Acesso em: 30 abr. 2013 b.

BRASIL. Ministério da Justiça. Secretaria de Reforma do Judiciário. Diagnóstico do Poder Judiciário. Brasília, 2004. 
ORDEM DOS ADVOGADOS DO BRASIL [OAB/BA]. OAB-BA entra com ação na Justiça Federal contra fechamento de comarcas. Disponível em: http://www.oabba.org.br/single-noticias/noticia/oab-entra-com-acao-na-justica-federal-contra-

fechamento-de-comarcas/?cHash=75873629c88b744957e997c4cc7639e8. Acesso em: 25 set. 2017.

TRIBUNAL DE CONTAS DA UNIÃO [TCU]. Realidade prisional: auditoria mostra que o custo mensal do preso é desconhecido em vários Estados. Disponível em: http://portal.tcu.gov.br/imprensa/noticias/realidade-prisional-auditoria-mostra-que-ocusto-mensal-do-preso-e-desconhecido-em-varios-estados.htm. Acesso em: 10 jan. 2018.

TRIBUNAL DE CONTAS DA UNIÃO. Tribunal de Contas realiza mapeamento de riscos na contratação de funções de confiança e de cargos em comissão. Disponível em: http://portal.tcu.gov.br/imprensa/noticias/tcu-realiza-mapeamento-de-riscos-na-

contratacao-de-funcoes-de-confianca-e-de-cargos-em-comissao.htm. Acesso em: 18 out. 2016a.

TRIBUNAL DE CONTAS DA UNIÃO TCU avalia governança e gestão de pessoas em órgãos federais. Disponível em: http://portal.tcu.gov.br/imprensa/noticias/tcu-avalia-governancae-gestao-de-pessoas-em-orgaos-federais.htm. Acesso em: 18 out. 2016b.

TRIBUNAL DE JUSTIÇA DO ESTADO DA BAHIA [TJBA]. Sessão do Tribunal Pleno aprova proposta de resolução para desativação de comarcas. Disponível em: http://www5.tjba.jus.br/index.php?option=com content\&view=article\&id=97366:sessaodo-tribunal-pleno-aprova-proposta-de-resolucao-para-desativacao-de-comarcas. Acesso em: 25 set. 2017. 